\title{
GERENCIAMENTO DE RESULTADOS PARA EVITAR A VIOLAÇÃO DOS COVENANTS CONTÁBEIS: EVIDÊNCIAS DO BRASIL
}

\author{
Jonatan Marlon Konraht 1 \\ Romualdo Douglas Colauto 2
}

- Artigo recebido em: 18/01/2020 -- Artigo aceito em: 26/08/2020 -" Segunda versão aceita em: 06/10/2020

\section{RESUMO}

A violação dos covenants implica uma série de consequências econômicas negativas para as empresas. Consequentemente, o risco de violá-los tende a incentivar as empresas a adotarem estratégias contábeis para evitar a violação. Estudos internacionais mostram que os gestores podem adotar estratégias contábeis para evitar a violação dos covenants, incluindo alterações explícitas de políticas contábeis, gerenciamento de resultados por accruals discricionários ou por decisões operacionais. Esta pesquisa analisa a relação entre a proximidade de violação dos covenants contábeis e o gerenciamento de resultados por meio de accruals discricionários, tendo como objetivo testar se as empresas brasileiras usam accruals discricionários para evitar a violação dos covenants. O estudo utiliza regressões com dados em painel, analisando 1223 observações trimestrais, correspondentes a 100 empresas de capital aberto que emitiram debêntures entre 2010 e 2016. As cláusulas referentes aos covenants consistiram nos indicadores Dívida Líquida/EBITDA e Dívida Líquida/Patrimônio Líquido. Os resultados indicam que gestores utilizam accruals discricionários para evitar a violação dos covenants contábeis à medida que eles se tornam mais próximos de serem estourados. A pesquisa contribui à literatura ao indicar que empresas brasileiras realizam escolhas contábeis alternativas às alterações em políticas contábeis divulgadas em notas explicativas, para tentar evitar a violação técnica da dívida. Esta pesquisa abre caminho para novos testes desta relação no Brasil, uma vez que sinaliza uma possível preferência de os gestores usarem acrruals discricionários ao invés de mudanças explícitas nas políticas contábeis para evitar a violação.

\footnotetext{
1 Mestre em Contabilidade pela Universidade Federal de Santa Catarina. Professor de Contabilidade do Instituto Federal do Paraná e doutorando em Contabilidade pela Universidade Federal do Paraná. Endereço: Rua. Eng. Tourinho, 829 - Vila Solene, Campo Largo - PR, 83607-140. Telefone: (41) 3208-8206. E-mail: jonatan.konraht@ifpr.edu.br. https://orcid.org/0000-0001-6586-6583

2 Pós-Doutor em Controladoria e Contabilidade pela FEA/USP. Doutor e Mestre em Engenharia de Produção na Área de Gestão de Negócios pela UFSC. Professor Associado IV do Departamento de Ciências Contábeis da UFPR. Endereço: Av. Prefeito Lothário Meissner, 632 - Jardim Botânico - CEP: 80210-070 - Curitiba - PR - Brasil - Telefone: (41) 3041-3182. E-mail: rdcolauto.ufpr@gmail.com.

https://orcid.org/0000-0003-3589-9389
}

Editor responsável pela aprovação do artigo: Dr. Eduardo Mendes Nascimento Editora responsável pela edição do artigo: Drª . Bruna Camargos Avelino 
Palavras-Chave: Covenants contábeis. Gerenciamento de resultados. Violação técnica. Debêntures.

\title{
EARNINGS MANAGEMENT TO AVOID DEBT COVENANT VIOLATIONS: EVIDENCE FROM BRAZIL
}

\begin{abstract}
Debt covenant violations implies several negative economic consequences for company. Consequently, the risk of breaching covenants tends to incentive companies to adopt accounting strategies to avoid this situation. International studies show that managers can use alternative accounting strategies to avoid covenant violations, including changes in accounting policies, earnings management or real earnings management. This research analyzes the relation between the proximity to debt covenant violation and the earnings management using discretionary accruals, with the purpose to test whether Brazilian companies use discretionary accruals to avoid covenant violations. We used panel data analyses with 1223 quarterly observations, corresponding to 100 companies listed on the Brazilian Stock Exchange that issued bonds among 2010-2016. The financial covenants analyzed consisted in the following financial indicators: Net Debt/EBITDA and Net Debt/Book value of Equity. We find evidence that managers use discretionary accruals to increase earnings and, thereby, to avoid debt covenant violations as they become closer to threshold. Our contribution to literature is to identify that Brazilian companies use implicit accounting choices as an alternative to changes in explicit accounting policies, such as disclosed in companies' Notes, to try to avoid covenant violations. This research opens the way for further testing of this relationship in Brazil, since the results signaling a possible managers' preference to use discretionary accruals rather than explicit changes in accounting policies to avoid covenant violation.
\end{abstract}

Keywords: Financial covenants. Earnings management. Debt covenant violations. Bonds.

\section{INTRODUÇÃO}

Este trabalho testa a Hipótese dos Covenants Contratuais no contexto das debêntures emitidas no Brasil, ao verificar a relação entre a proximidade de violação dos coventans contábeis e o gerenciamento de resultados por meio de accuals discricionários. Os covenants contábeis consistem em cláusulas contratuais que utilizam dados contábeis para monitorar a situação econômica e/ou financeira da empresa devedora. Caso ela não consiga se enquadrar nestes covenants, ocorre a violação técnica da dívida. A violação implica em os credores passarem a ter direito de exigir a antecipação do pagamento da dívida, bem como uma série de outras consequências indiretas para a empresa e seus gestores, tal como aumento do custo da dívida, reestruturação da dívida e demissão dos gestores (Nini, Smith, \& Sufi, 2012).

Tomadas as consequências econômicas da violação técnica, os gestores tenderão a utilizar discricionariedade para selecionar políticas contábeis com o 
intuito de reduzir a probabilidade de violação dos covenants (Watts \& Zimmerman, 1990). Esta previsão teórica é denominada de Hipótese dos Covenants Contratuais.

A Hipótese dos Covenants Contratuais já foi foco de estudos realizados no mercado norte-americano. Em geral, os estudos indicam que os gestores tendem a adotar estratégias contábeis para influenciar os números contábeis e reduzir a probabilidade de violação dos covenants (Dichev \& Skinner, 2002). Além disso, a literatura aponta que os gestores podem adotar diversos mecanismos para alterar o resultado contábil e evitar a violação técnica, incluindo alterações voluntárias nas políticas contábeis divulgadas em notas explicativas (mudanças explícitas), tal como mudança no método de mensuração de estoques e critérios de depreciação (Sweeney, 1994); gerenciamento dos accruals discricionários por meio de mudanças nas políticas contábeis que não precisam ser divulgadas em notas explicativas (mudanças implícitas), tal como aceleração e postergação do reconhecimento de receitas e despesas (DeFond \& Jiambalvo, 1994; Jha, 2013; Franz, HassabElnaby, \& Lobo, 2014); e gerenciamento de resultados por decisões operacionais (Healy \& Palepu, 1990; Franz et al., 2014).

Em contraponto às evidências documentadas no mercado norteamericano, os resultados do teste da Hipótese dos Covenants Contratuais no ambiente institucional brasileiro não suportaram as previsões teóricas dessa hipótese. Especificamente, Silva (2008) constatou que os gestores não realizam alterações voluntárias de políticas contábeis explícitas, tal como critério de avaliação de estoques e imobilizados, capitalização de juros, contabilização de arrendamento mercantil financeiro, dentre outros, com o intuito de evitar a violação técnica da dívida à medida que aumenta a proximidade de violação dos covenants. Dentre as possíveis explicações para esse panorama, constam o baixo custo da violação técnica (Silva, 2008), e as características institucionais do mercado brasileiro, tal como baixa proteção aos direitos dos credores e baixo enforcement legal (Hong, Hung \& Zhang, 2016), as quais reduzem o incentivo dos gestores em evitar a violação técnica.

No entanto, outro fator que pode explicar esta divergência dos resultados nacionais em relação aos estudos norte-americanos é a possibilidade de os gestores adotarem estratégias contábeis alternativas às mudanças nas políticas contábeis explícitas para evitar a violação técnica, tal como realizar alteração nas políticas contábeis implícitas ou gerenciar resultados por meio de decisões operacionais. Diante disso, esta pesquisa se propõe a preencher parte dessa lacuna ao analisar se as empresas brasileiras utilizam os accruals discricionários para reduzir a probabilidade de violação dos covenants contábeis. Assim, apresenta-se a seguinte inquietação: A proximidade de violação dos covenants contábeis influencia 0 gerenciamento de resultados por meio de accruals discricionários no Brasil? Consequentemente, o objetivo desta pesquisa é identificar a relação entre a proximidade de violação dos covenants contábeis e o gerenciamento de resultados por meio de accruals discricionários no Brasil.

Metodologicamente, a proximidade de violação técnica foi mensurada por meio de uma medida de proximidade relativa de violação de cada indicador contábil vigente das debêntures das empresas, enquanto o gerenciamento de resultados foi estimado pelo modelo de Jones (1991), com modificação proposta por Dechow, Sloan e Sweeney (1995). Os resultados indicam haver relação positiva entre proximidade de violação e quantidade de accruals discricionários, 
o que sugere que os accruals discricionários são utilizados para evitar a violação técnica da dívida à medida que os covenants contábeis se tornam mais próximos de serem estourados.

A principal diferença metodológica deste estudo em relação ao de Silva (2008) consiste na observação das práticas contábeis adotadas pelos gestores para se evitar a violação dos covenants contábeis, em que este estudo analisa o uso do gerenciamento de resultados por meio de accruals discricionários, o qual inclui os efeitos das mudanças implícitas e explícitas de políticas contábeis, enquanto Silva (2008) analisou as mudanças voluntárias de práticas contábeis evidenciadas em notas explicativas. Esta pesquisa também difere em relação ao período analisado. No tocante ao período de análise desta pesquisa em relação ao de Silva (2008), tem-se que o período atual continua configurando o ambiente brasileiro como de baixo enforcement legal e proteção aos credores, comparativamente aos países com mercado de capitais mais desenvolvidos (Hong et al., 2016), fatores que podem desincentivar o gerenciamento de resultados para evitar a violação dos covenants contábeis. No entanto, o período analisado nesta pesquisa é posterior à adoção das International Financial Reporting Standards (IFRS) no Brasil, o que pode ter aumentado a capacidade dos gestores em usar práticas contábeis para evitar a violação técnica dos covenants contábeis. Ball, Li e Shivakumar (2015) relatam que a adoção das IFRS trouxe maior discricionariedade aos gestores na seleção de métodos contábeis, aumentando a capacidade de alterar políticas contábeis para evitar a violação dos covenants, o que contribuiu para redução da inserção de covenants contábeis nos instrumentos de dívida. Efeito similar também é documentado no Brasil, em que Beiruth, Fávero, Murcia, Almeida e Brugni (2017) constataram que, após a adoção das IFRS, houve redução proporcional no uso de covenants contábeis, em relação aos não contábeis, nas debêntures emitidas no Brasil. Assim, esta pesquisa se diferencia por examinar a resposta dos gestores através de accruals discricionários, os quais podem captar ambas as formas de alteração do resultado contábil, implícitas e explícitas, se mostrando mais abrangente para captar a resposta contábil dos gestores frente à proximidade de violação, bem como por analisar um período pós-adoção das IFRS, o que pode ter gerado a discricionariedade necessária para os gestores usarem práticas contábeis para evitar a violação dos covenants contábeis.

Dessa forma, a pesquisa contribui à literatura nacional ao complementar os achados de Silva (2008), no sentido de indicar que os gestores podem estar utilizando estratégia contábil alternativa à mudança de políticas contábeis explicitadas nas notas explicativas para tentarem evitar a violação técnica da dívida, a qual consiste especificamente em mudanças de políticas contábeis que não precisem ser evidenciadas em notas explicativas. Esse fenômeno pode ser parcialmente explicado por conta das mudanças nos accruals discricionários provocadas pelas políticas não explicitadas em notas explicativas serem menos visíveis (Healy \& Palepu, 1990) e menos custosas (DeFond \& Jiambalvo, 1994) do que as mudanças explícitas. Assim, esses resultados sinalizam uma possível preferência das empresas brasileiras em utilizar mudanças de políticas contábeis implícitas, ao invés daquelas que precisam ser evidenciadas em notas explicativas, para evitar a violação técnica da dívida.

No tocante à literatura estrangeira, este estudo se diferencia por, além de analisar um país de baixo enforcement legal e proteção aos credores (Hong et 
al., 2016), analisar o incentivo gerado pelos covenants contábeis de debêntures para se evitar a violação técnica da dívida, uma vez que os demais estudos que testaram a Hipótese dos Covenants Contratuais foram desenvolvidos, sobretudo, no mercado de empréstimos/financiamentos bancários estadunidense. A literatura de covenants financeiros aponta evidências de que a captação de dívida via debêntures contém menor quantidade de covenants contábeis (Mather \& Peirson, 2006; Chava, Fang, Kumar, \& Prabhat, 2019) e covenants menos rígidos do que os empréstimos/financiamentos bancários (Dichev \& Skinner, 2002; Mather \& Peirson, 2006), o que pode reduzir a necessidade e incentivo de se gerenciar resultados para evitar a violação técnica da dívida.

Por outro lado, a renegociação da dívida via debêntures, em caso de violação técnica, tende a ser mais complexa do que a dos empréstimos/financiamentos bancários, dada a necessidade de que as decisões de negociação terem de ser aprovadas por ampla maioria dos debenturistas em assembleia geral (Konraht, 2017), o que pode aumentar os custos e consequências econômicas das violações, incentivando a gestão a evita-las. Assim, a pesquisa é relevante no âmbito internacional por adicionar evidências de que o risco de violação técnica de covenants contábeis das debêntures também gera incentivos para que os gestores adotem práticas contábeis para evita-las.

Por fim, os resultados fornecem indícios de que a prática de gerenciamento de resultados para evitar a violação técnica da dívida é consistente tanto em covenants da classe capital covenants quanto nos da classe performance covenants, o indica que a característica de os performance covenants tenderem a ter maior facilidade na renegociação da dívida não anula os incentivos dos gestores para evitar a violação deles.

\section{REVISÃO DA LITERATURA E DESENVOLVIMENTO DA HIPÓTESE}

Os covenants contábeis consistem em cláusulas contratuais que utilizam indicadores financeiros para estabelecer limites à situação econômica e/ou financeira da empresa, tal como o nível máximo de endividamento ou o nível mínimo de rentabilidade que a empresa deve manter durante a vigência da dívida (Mather \& Peirson, 2006). Essas cláusulas são inseridas nos contratos de captação de financiamento com a finalidade de mitigar conflitos de agência entre empresa e credores, decorrentes da ação oportunista dos gestores e/ou acionistas (Smith \& Warner, 1979), bem como para facilitar a renegociação da dívida, em caso de ocorrência de eventos contingenciais impossíveis de serem determinados no momento da contratação de dívidas (Demerjian, 2017).

Caso a empresa não consiga manter seus indicadores financeiros dentro dos limites fixados nos covenants contábeis, ocorre a violação técnica da dívida (technical default) (Taylor, 2013). A violação técnica garante aos credores o direito de acelerar total ou parcialmente o pagamento da dívida (Nini et al., 2012). No entanto, evidências empíricas demonstram que a prática mais comum adotada pelos credores, no evento de violação técnica, é a utilização desse direito para estabelecer a renegociação dos termos da dívida junto aos devedores (Nini et al., 2012). Na ocorrência da violação técnica, há também possibilidade de os credores concederem o perdão (waiver) temporário à 
violação, por meio da concessão de prazos para a empresa regularizar o indicador financeiro ou conceder perdão permanente à violação, situação em que os credores revogam por tempo indeterminado os direitos gerados pela violação técnica sem impor penalidades à empresa ou reestruturarem a dívida (Chen \& Wei, 1993; Jaggi \& Lee, 2002).

Pesquisas anteriores demonstram que, independente da penalização imposta para a violação técnica da dívida, ela sempre implica em custos à empresa devedora ou aos seus gestores, mesmo que a empresa receba o perdão da violação (Beneish \& Press, 1993; Nini et al., 2012). Especificamente, as evidências empíricas indicam que a violação técnica implica em custos diretos, pois aumenta as taxas de juros nas renegociações da dívida violada (Nini et al., 2012); aumenta o custo da dívida das novas captações de recursos (Freudenberg, Imbierowicz, Saunders, \& Steffen, 2017); aumenta o custo de capital próprio (Ngo, Duong, \& Chen, 2016); e aumenta o custo de auditoria (Bhaskar, Krishnan, \& Yu, 2017; Gao, Khan, \& Tan, 2017). Além desses custos diretos, a violação técnica pode gerar consequências indiretas à empresa e seus gestores, tal como o aumento da probabilidade de turnover do Chief Executive Officer (CEO) (Nini et al., 2012); cortes na política de investimentos (Nini et al., 2012); cortes na política de distribuição de dividendos (Nini et al., 2012; Bulan \& Hull, 2013); piores condições contratuais na captação de novos empréstimos/financiamentos (Freudenberg et al., 2017); além de poder implicar na violação técnica cruzada de covenants contidos em outros contratos de financiamento (Dichev \& Skinner, 2002).

Nesse sentido, pesquisas anteriores sugerem que essas consequências econômicas negativas geradas pela violação técnica da dívida configuram um potencial conjunto de incentivos para que os gestores utilizem seu poder discricionário para selecionar políticas contábeis com o objetivo evitar a violação dos covenants contábeis e os custos decorrentes dela (Dichev \& Skinner, 2002; Jha, 2013; Franz et al., 2014). Essa situação tem sido estudada sob a denominação de Hipótese dos Covenants Contratuais, a qual prevê que, à medida que a empresa se aproxima da violação dos covenants contábeis, maior é o incentivo para que os gestores adotem políticas contábeis que contribuam para reduzir a probabilidade de violação (Watts \& Zimmerman, 1990).

Embora a Hipótese dos Covenants Contratuais seja bastante difundida na literatura, os resultados empíricos das pesquisas que analisaram a utilização de accruals discricionários para evitar a violação dos covenants contábeis não são unânimes. DeFond e Jiambalvo (1994) e Jha (2013), ao analisarem amostras de empresas que evidenciaram alguma violação de covenants contábeis, constataram que, no período que antecede a violação, os gestores utilizam os accruals discricionários para gerenciar os resultados na tentativa de evitar a violação técnica da dívida.

Franz et al. (2014) analisaram uma amostra de empresas com e sem violação técnica da dívida, e constataram que empresas próximas da violação do indicador contábil utilizado no covenant gerenciam mais os resultados para aumentar o lucro. Embora Franz et al. (2014) tenham utilizado uma abordagem metodológica diferente de DeFond e Jiambalvo (1994) e Jha (2013), ambos sugerem que os gestores respondem ao incentivo de evitar os custos da violação técnica por meio do gerenciamento de resultados para aumentar o resultado. 
Jaggi e Lee (2002) constataram que a direção do gerenciamento de resultados, na eminência da violação técnica da dívida, depende da probabilidade de a firma receber o perdão dos credores para a violação. Sendo assim, se os gestores possuem perspectivas de receber o perdão da violação, eles tendem a aumentar o resultado do período para facilitar a negociação com os credores e aumentar a probabilidade de receber o perdão da violação; por outro lado, se a perspectiva é de que os credores não concedam o perdão, os gestores tendem a piorar ainda mais a situação econômica da empresa para destacar suas dificuldades financeiras $e$, assim, conseguirem barganhar melhores condições contratuais na reestruturação da dívida junto aos credores (Jaggi \& Lee, 2002).

O teste da Hipótese dos Covenants Contratuais realizado por Silva (2008), no Brasil, não apontou evidências que suportassem as predições teóricas dessa hipótese. $O$ autor analisou 125 empresas que possuíam covenants contábeis em contratos de financiamento de longo prazo junto a um grande banco público federal ou emissão de dívida por meio de debêntures. O autor constatou que as empresas não realizam mudanças voluntárias de práticas contábeis evidenciadas em notas explicativas para aumentar o resultado à medida que os covenants contábeis se aproximam da violação técnica. Dentre as explicações para esse resultado, Silva (2008) sugere: (a) forte normatização e fiscalização contábil no país; (b) falta de flexibilidade na seleção das políticas contábeis pelas empresas, uma vez que elas já utilizavam políticas que maximizavam o resultado contábil; e, (c) baixo custo das consequências econômicas das violações técnicas no Brasil.

Além das explicações levantadas por Silva (2008), outro fator que pode explicar o fato de as empresas brasileiras não utilizarem as mudanças de políticas contábeis explícitas para evitar a violação técnica é a possibilidade de elas utilizarem mudanças contábeis implícitas ou praticarem gerenciamento de resultados por decisões operacionais para atingir este fim. Nesse sentido, Healy e Palepu (1990) destacam que a aceleração ou postergação das receitas e despesas (mudanças de políticas contábeis não divulgadas em notas explicativas), por meio dos accruals discricionários, é uma maneira alternativa às mudanças de políticas contábeis explícitas para que os gestores evitem a violação técnica da dívida. A vantagem de se utilizar as alterações das políticas contábeis não evidenciadas em notas explicativas é que elas são menos visíveis aos usuários externos (Healy \& Palepu, 1990) e menos custosas (DeFond \& Jiambalvo, 1994) do que as mudanças nos métodos contábeis explícitos. Consequentemente, os gestores das firmas brasileiras podem preferir tentar evitar a violação técnica da dívida através de mudanças em políticas contábeis implícitas, ao invés de modificar as políticas contábeis explicitadas em notas explicativas.

Assim, depreende-se que os custos da violação técnica dos covenants contábeis geram incentivos para que os gestores usem a discricionariedade sobre a seleção de critérios contábeis para aumentar o resultado contábil. Dessa forma, o aumento no resultado provocaria aumento nos indicadores de desempenho (Receita, Lucro Bruto, Lucro Líquido etc.) e no Patrimônio Líquido (PL), o que faria com que a apuração dos indicadores financeiros relacionados ao desempenho econômico e PL fossem melhorados, reduzindo a probabilidade de violação dos covenants. No entanto, a resposta contábil dos gestores diante desses incentivos 
é uma questão de análise empírica, uma vez que eles podem utilizar diferentes estratégias contábeis para evitar a violação. Dessa forma, formula-se a seguinte hipótese de pesquisa para se testar a previsão tradicional da Hipótese dos Covenants Contratuais:

Hipótese: A proximidade de violação dos covenants contábeis incentiva os gestores a utilizarem accruals discricionários para aumentar o resultado contábil do período.

\section{PROCEDIMENTOS METODOLÓGICOS}

\subsection{Amostra e Período de Análise}

Os covenants contábeis analisados nesta pesquisa correspondem àqueles utilizados nas debêntures emitidas entre os anos de 2010 e 2016 pelas empresas não financeiras listadas na Bolsa Brasil Balcão - B33. Optou-se pelos covenants presentes nas debêntures em razão das escrituras e os prospectos de debêntures serem documentos divulgados, o que possibilita o acesso aos dados sobre os indicadores contábeis a eles atrelados, bem como os seus respectivos limites que desencadeiam a violação. Nesse sentido, destaca-se que, embora as debêntures tenham covenants contábeis menos restritivos do que os empréstimos/financiamentos, elas tendem a ter consequências econômicas mais custosas em caso de violação técnica, dada a maior dificuldade de renegociação da dívida junto aos credores por conta da dispersão deles (Mather \& Peirson, 2006). Como implicação, essa característica pode aumentar o incentivo dos gestores para tentar evitar a violação técnica desses títulos de dívida.

Foram identificadas 393 escrituras e/ou prospectos de debêntures disponíveis para download no Sistema Nacional de Debêntures, as quais correspondem tanto à modalidade de emissão com esforços restritos (Instrução Normativa $\mathrm{CVM}^{\circ} \mathrm{n}^{476}$ ) quanto à modalidade de destinada ao público em geral (Instrução Normativa CVM n 400). Desse total, 296 títulos, emitidos por 132 empresas, continham ao menos um covenant contábil a ser cumprido pela empresa emissora da dívida.

Posteriormente à identificação das debêntures que possuíam covenants contábeis, procedeu-se à coleta das características dos covenants contábeis, em relação ao indicador contábil utilizado e ao limite fixado como gatilho para a violação técnica. Foram identificados 569 covenants contábeis a serem cumpridos pela empresa emissora da dívida, os quais estavam distribuídos entre 87 indicadores financeiros diferentes.

Apesar da diversidade de indicadores financeiros utilizados como covenants contábeis, constatou-se predomínio de indicadores relacionados ao Lucro Antes dos Juros, Tributos Sobre o Lucro, Depreciação e Amortização (EBITDA) e à Dívida Líquida, tal como observado nos índices "Dívida Líquida/EBITDA", "EBITDA/Resultado Financeiro", "Dívida Líquida/Patrimônio Líquido" e "EBITDA/Despesas Financeiras". Na Tabela 1 são apresentados os indicadores contábeis mais frequentemente utilizados nas escrituras e/ou prospectos de debêntures analisadas. 
Tabela 1

Principais indicadores contábeis utilizados nas debêntures da amostra

\begin{tabular}{|c|c|c|}
\hline Indicador utilizado & Frequênciaa & Proporçãob \\
\hline Dívida Líquida/EBITDA & 236 & $80 \%$ \\
\hline EBITDA/Resultado Financeiro & 125 & $42 \%$ \\
\hline Geração de caixa/(Amortizações do principal + Juros) & 33 & $11 \%$ \\
\hline Dívida Líquida/Patrimônio Líquido & 26 & $9 \%$ \\
\hline EBITDA/Despesas Financeiras & 24 & $8 \%$ \\
\hline (Dívida líquida + imóveis a pagar)/PL & 10 & $3 \%$ \\
\hline Geração de caixa/Obrigações de curto prazo & 10 & $3 \%$ \\
\hline Patrimônio Líquido/Ativo total & 9 & $3 \%$ \\
\hline Ativo Circulante/Passivo Circulante & 7 & $2 \%$ \\
\hline Limite à distribuição de dividendos & 7 & $2 \%$ \\
\hline EBIT/Resultado Financeiro & 6 & $2 \%$ \\
\hline Outros indicadores* & 76 & $26 \%$ \\
\hline
\end{tabular}

Nota: * O grupo Outros indicadores é composto por 40 indicadores financeiros diferentes, presentes, em média, em duas debêntures.

a quantidade de debêntures que utiliza este indicador como covenant contábil.

b Proporção em relação às debêntures com covenants contábeis.

Legenda: EBITDA: Lucro Antes dos Juros, Tributos Sobre o Lucro, Depreciação e Amortização; EBIT: Lucro Antes dos Juros e Tributos Sobre o Lucro; PL: Patrimônio Líquido.

Fonte: Elaborada pelos autores.

A partir dos indicadores identificados, foi adotado o critério de selecionar o indicador mais utilizado de cada uma das duas classes de covenant contábeis: performance covenants e capital covenants (Demerjian, 2011; Christensen \& Nikolaev, 2012). Performance covenants consistem em cláusulas restritivas baseadas em indicadores financeiros de desempenho e utilizam dados provenientes da Demonstração do Resultado, da Demonstração dos Fluxos de Caixa ou índices calculados a partir delas, tal como o indicador Dívida Líquida/EBITDA (Christensen \& Nikolaev, 2012). A finalidade dos performance covenants é atuar como gatilho para renegociação da dívida na hipótese da situação econômica da firma se deteriorar acima do limite estipulado no covenant contábil (Demerjian, 2017). Os capital covenants correspondem aos indicadores calculados exclusivamente a partir do Balanço Patrimonial, a exemplo do indicador Dívida Líquida/Patrimônio Líquido. O objetivo desses covenants é alinhar os interesses dos acionistas e dos credores, pois obrigam os acionistas a manter um nível mínimo de capital investido (Christensen \& Nikolaev, 2012).

O critério de selecionar um covenant de cada classe justifica-se por conta de Christensen e Nikolaev (2012) constatarem que essas duas classes de covenants se diferenciam em relação à probabilidade de renegociação da dívida, sendo que os empréstimos/financiamentos que utilizam os performance covenants possuem maior probabilidade de serem renegociados, receberem perdão da violação ou receberem o reset dos covenants contábeis, do que os empréstimos/financiamentos que utilizam os capital covenants. Assim, a seleção dessas duas classes possibilita a identificação da resposta dada pelos gestores aos incentivos de se evitar a violação técnica de cada classe de covenant contábil. Dessa forma, foram selecionados os indicadores "Dívida Líquida/EBITDA" e "Dívida Líquida/Patrimônio Líquido" para testes inferenciais sobre a utilização de práticas de gerenciamento de resultados quando da proximidade de violação dos covenants. 


\subsection{Variável Dependente: Gerenciamento de Resultados}

A variável dependente deste estudo é o gerenciamento de resultados (GR) por meio dos accruals discricionários. O nível de gerenciamento de resultados foi estimado para cada trimestre, por meio do modelo de Jones (1991), modificado por Dechow et al. (1995) (o qual captura os acruals discricionários totais em um determinado período). Essa estimação é apresentada na Equação 1. Nesse modelo, o nível de gerenciamento de resultados corresponde ao resíduo $\left(\varepsilon_{i, t}\right)$ estimado a partir da diferença entre o valor real observado para os accruals totais e o valor estimado a partir dos parâmetros estimados pela regressão. Valores positivos indicam uso dos accruals discricionários para aumentar o resultado corrente, enquanto que valores negativos indicam gerenciamento de resultados para se reduzir o resultado. Para evitar um possível viés de seleção na estimação do GR, a amostra usada para se estimar os accruals discricionários consistiu em todas as empresas não financeiras com dados disponíveis na Economatica ${ }^{\circledR}$; assim, a amostra usada para estimação do GR conta com companhias com e sem incentivos para cumprirem covenants contábeis.

$$
\frac{A T_{i, t}}{A_{i, t-1}}=\alpha_{1}\left(\frac{1}{A_{i, t-1}}\right)+\alpha_{2}\left(\frac{\Delta R L_{i, t}-\Delta C R_{i, t}}{A_{i, t-1}}\right)+\alpha_{3}\left(\frac{A I_{i, t}}{A_{i, t-1}}\right)+\varepsilon_{i, t}
$$

Em que,

AT: Accruals totais calculados pela diferença entre o lucro líquido e o fluxo de caixa operacional.

A: Ativo total.

$\Delta R L:$ Variação da Receita Líquida do perío do t-1 para o período t.

$\Delta$ CR: Variação do saldo de Contas a Receber do período t-1 para o período t.

Al: Soma do saldo bruto das contas Ativo Imobilizado e Ativo Intangível.

$\varepsilon:$ Resíduo da regressão e estimativa do gerenciamento de resultados pelo modelo de Jones Modificado.

\subsection{Variável de Interesse: Proximidade de Violação Técnica}

Para capturar o incentivo dos gestores em evitar a violação técnica da dívida, foi calculada uma variável representativa da proximidade de violação dos covenants contábeis. Essa variável foi calculada trimestralmente pela subtração do limite estabelecido para o indicador na cláusula restritiva e a situação real do indicador financeiro da empresa, e, posteriormente, relativizada pelo limite contratual estabelecido no covenant contábil. O resultado deste cálculo indica o percentual de folga entre a situação atual do indicador financeiro da empresa e o limite máximo estabelecido no covenant contábil, sendo que quanto maior a folga, mais distante a empresa está da violação do covenant. Isso implicaria em uma relação inversa entre folga e incentivo ao gerenciamento de resultados. Portanto, para fins de melhor compreensão da análise de dados, foi realizada uma inversão matemática de sinal no cálculo da proximidade de violação para que ela passasse a ter relação direta com o gerenciamento de resultados, ou seja: quanto maior o valor da variável "proximidade de violação", mais próxima a empresa está da violação técnica do covenant e maior é o incentivo para gerenciar os resultados para cima. Valores positivos, após a inversão matemática, indicam que já ocorreu a violação do

106 Revista Contabilidade Vista \& Revista, ISSN 0103-734X, Universidade Federal de Minas Gerais, Belo Horizonte, v. 32, n. 2, p. 97-121, maio/ago. 2021 
indicador. Na Equação 2 é apresentada a fórmula de cálculo da proximidade de violação dos covenants contábeis.

$$
\text { Proximidade de violação }=\frac{(\text { Limite do indicador }- \text { Situação atual do indicador })}{\text { Limite do indicador }} \times(-1)
$$

A Equação 2 é aplicável aos covenants que estabelecem limites máximos à apuração dos indicadores, tal como é o caso dos dois covenants selecionados nesta pesquisa. Ambos mensuram o risco de insolvência da empresa devedora, sendo que quanto maior o valor do indicador, maior é o risco. Portanto, os credores estipulam limites máximos para tais indicadores em forma de covenant contábil, como forma de restringir o risco máximo a que estão expostos durante a vigência da dívida.

Quando a empresa apresenta valor negativo para EBITDA ou PL, há necessidade de se realizar um ajuste na Equação 2 para garantir o cálculo adequado da proximidade de violação. Situações de valores negativos para o EBITDA implicam necessariamente na violação dos covenants do tipo Dívida Líquida/EBITDA, dado que o resultado da apuração desse indicador é inferior a zero. Assim, nas situações de EBITDA negativo a ordem dos elementos da subtração do numerador da Equação 2 foi invertida, passado a ser (situação atual do indicador - limite do indicador). Situação similar ocorre quando $\mathrm{PL}$ apresenta valor negativo na apuração do indicador Dívida Líquida/PL, o que também requer ajuste de inversão da subtração. No entanto, não ocorreram situações de PL negativo na apuração do indicador Dívida Líquida/PL na base de dados. Situações em que apenas o índice Dívida Líquida (DL) apresenta valor negativo, devido aos saldos de caixa e aplicações financeiras da empresa somarem valor superior ao passivo oneroso, não requerem ajuste na Equação 2. Por fim, vale ressaltar que não ocorreram situações em que tanto o numerador quanto o denominador dos indicadores Dívida Líquida/EBITDA e Dívida Líquida/PL apresentaram valores negativos, o que também requereria um tratamento para adequação do cálculo.

A utilização de uma variável de proximidade de violação ao invés de uma amostra de empresas que apresentaram violação dos covenants contábeis tem como vantagem o fato de captar tanto as tentativas bem-sucedidas de evitar a violação técnica por meio do gerenciamento de resultados (empresas que gerenciaram e conseguiram evitar a violação técnica) quanto as tentativas que fracassaram (empresas que gerenciaram, mas que não conseguiram evitar a violação dos covenants).

Durante a coleta de dados foi constatado que, em algumas escrituras e/ou prospectos de debêntures, o limite dos covenants contábeis variava ao longo da vida da dívida. Nesses casos, os cálculos trimestrais da proximidade de violação foram ajustados em cada trimestre de acordo com as especificações contratuais para que o indicador refletisse a real proximidade de violação em cada um dos períodos analisados.

Quando uma empresa tinha mais de uma debênture em circulação com os mesmos indicadores financeiros, o critério adotado foi a seleção da cláusula com 
o limite mais próximo da violação técnica, uma vez que este limite gera mais incentivos para o gerenciamento de resultados no período em análise.

Durante a fase de leitura da especificação contratual do cálculo dos indicadores contábeis nas debêntures, foi constatado que alguns deles eram customizados com adições ou exclusões de contas específicas à formula padrão dos índices financeiros tradicionalmente apresentados na literatura contábil. Consequentemente, tornou-se inviável realizar trimestralmente todos os cálculos seguindo os ajustes contratuais especificados nas debêntures. Por conta disso, uma potencial limitação deste estudo é que a proximidade de violação calculada na pesquisa e a proximidade real apurada pelos agentes fiduciários pode sofrer pequenas diferenças. Essa limitação metodológica implica que, pequenos valores positivos apurados no cálculo da Equação 2 podem, na prática, não representar a violação do covenant contábil devido a adições no numerador ou exclusões no denominador da fórmula estabelecida nas debêntures. Assim, para a determinação da violação técnica, foi adotado como proxy uma margem de $10 \%$ no limite estabelecido na cláusula restritiva. Isso indica que foram considerados como violados os covenants que apresentaram desempenho real, calculado na pesquisa a partir da fórmula padrão dos indicadores financeiros, $10 \%$ acima do limite estabelecido como ponto de violação técnica no contrato de dívida.

Vale ressaltar que as empresas não foram separadas em "violadas" e "não violadas" para a análise de dados. Para as análises de regressão, a proximidade de violação foi tratada na sua forma de variável métrica, tal como apresentado na Equação 2. A proxy de violação foi utilizada para determinação das empresas que apresentaram a primeira violação técnica. As observações posteriores à primeira violação da dívida da empresa foram retiradas da amostra de dados. Esse procedimento metodológico é necessário por conta da violação técnica das debêntures comumente implicar na renegociação da dívida com modificação dos seus termos contratuais iniciais, incluindo os covenants (Silva, 2008). Assim, após a ocorrência da primeira violação técnica da dívida, é possível que os covenants inicialmente coletados tenham seus limites modificados. Isso poderia causar viés no cálculo da proximidade de violação, caso as observações posteriores à primeira violação fossem mantidas na amostra.

\subsection{Modelo da Pesquisa}

Para o teste empírico da hipótese da pesquisa, os dados coletados foram analisados por meio de análise de regressão com dados em painel, em que o gerenciamento de resultados é a variável dependente e a proximidade de violação técnica é a variável de interesse das análises. Além dessas duas variáveis, foram inseridas no modelo variáveis de controle que representam outros incentivos para os gestores praticarem gerenciamento de resultados, as quais consistem no tamanho da empresa, nível de endividamento, crescimento das vendas, rentabilidade e setor econômico. Foram adicionadas dummies trimestrais e anuais para controlar, respectivamente, efeitos sazonais dos ciclos de negócios sobre os accruals das empresas e efeitos macroeconômicos sobre o incentivo dos gestores ao gerenciamento de resultados.

A literatura sobre gerenciamento de resultados documenta que uma das motivações para se gerenciar resultados é para reduzir custos políticos (Watts \& 
Zimmerman, 1990; Richardson, 2000). Ademais, pesquisas internacionais (Richardson, 2000) e nacionais (Nardi \& Nakao, 2009; Barros, Menezes, Colauto, \& Teodoro, 2014) apontam evidências de que empresas maiores tendem a gerenciar os resultados para baixo. Assim, espera-se uma relação negativa entre tamanho e gerenciamento de resultados, uma vez que empresas maiores possuem incentivos para gerenciar resultados para baixo com o intuito de reduzir custos políticos (Watts \& Zimmerman, 1990).

Embora a Hipótese do Grau de Endividamento preveja que empresas com maiores níveis de endividamento tenham incentivos para gerenciar os resultados para cima (Watts \& Zimmerman, 1990), as evidências documentadas no Brasil são mistas em relação ao efeito do endividamento sobre gerenciamento de resultados, tal como pode ser observado nos resultados obtidos por Coelho e Lopes (2007), Nardi e Nakao (2009), Ardison, Martinez e Galdi (2012), Barros et al. (2014) e Sincerre, Sampaio, Famá e Santos (2016). Assim, optou-se por manter em aberto a expectativa da relação entre endividamento e GR.

Em relação ao crescimento, Gu, Lee e Rosset (2005) argumentam que empresas com maiores taxas de crescimento possuem maior incentivo para gerenciar resultados contábeis, uma vez que os recursos utilizados para financiar a expansão são captados no mercado financeiro ou gerados internamente pela empresa. Ademais, Nardi e Nakao (2009) e Barros et al. (2014) encontraram relação positiva entre crescimento e gerenciamento de resultados no ambiente brasileiro. Assim, espera-se relação positiva entre crescimento e GR.

Por fim, considerando que as empresas possuem incentivos para utilizar os accruals tanto para aumentar quanto para diminuir o resultado contábil, tem-se que a relação entre $G R$ e rentabilidade depende da motivação para o gerenciamento. Em linha com este argumento, resultados de estudos empíricos realizados no Brasil indicam que a relação entre o retorno sobre os ativos (ROA) e o gerenciamento de resultados ainda não é clara, sendo que há evidências empíricas de relações positiva (Sincerre et al., 2016), negativa (Barros et al., 2014) e nula (Nardi \& Nakao, 2009). Dessa forma, manteve-se em aberto a relação esperada entre a rentabilidade e o gerenciamento de resultados. Semelhantemente, por conta de os efeitos dos setores econômicos, períodos trimestrais e anuais variarem, foi mantida em aberta a relação esperada para tais variáveis e o GR.

O modelo econométrico da relação testada nesta pesquisa é apresentado na Equação 3. Os resultados do modelo servem de base para o teste da hipótese da pesquisa e alcance do objetivo do estudo. Valores positivos e estatisticamente significantes para o coeficiente beta $1\left(\beta_{1}\right)$ indicam que, em média, o gerenciamento de resultados aumenta à medida que os covenants se aproximam da violação.

$$
\begin{aligned}
\text { GR }_{i, t}=\alpha_{i, t}+ & \beta_{1} \text { Proximidade de violação }_{i, t}+\beta_{2} \text { Tamanho }_{i, t}+\beta_{3} \text { Endividamento }_{i, t} \\
& +\beta_{4} \text { Crescimento das vendas }_{i, t}+\beta_{5} \text { Rentabilidade }_{i, t} \\
& +\sum_{k=1}^{4} \delta_{k} \text { TRIMESTRE }_{k}+\sum_{d=2010}^{2017} \theta_{d} \text { ANO }_{d}+\sum_{j=1}^{15} \gamma_{j} \text { SETOR }_{j, i}+\varepsilon_{i, t}
\end{aligned}
$$


A operacionalização das variáveis utilizadas no modelo é demonstrada na Tabela 2.

\section{Tabela 2}

Operacionalização das variáveis da pesquisa

\begin{tabular}{|c|c|c|c|}
\hline Variável & Tipo & Operacionalização & $\begin{array}{l}\text { Relação } \\
\text { esperada }\end{array}$ \\
\hline $\begin{array}{l}\text { Gerenciamento de } \\
\text { resultados (GR) }\end{array}$ & Dependente & Jones Modificado (1995). & - \\
\hline $\begin{array}{l}\text { Proximidade de } \\
\text { violação dos } \\
\text { covenants contábeis }\end{array}$ & Interesse & Equação 2. & Positiva \\
\hline $\begin{array}{l}\text { Tamanho da } \\
\text { empresa }\end{array}$ & Controle & Logaritmo natural do Ativo Total. & Negativa \\
\hline Endividamento & Controle & Passivo exigível/Patrimônio Líquido & Em aberto \\
\hline $\begin{array}{l}\text { Crescimento das } \\
\text { vendas }\end{array}$ & Controle & (Receita Líquidat/Receita Líquidat-1) -1 & Positiva \\
\hline Rentabilidade & Controle & Lucro líquido/Ativo Médio. & Em aberto \\
\hline Setor & Controle & $\begin{array}{l}\text { Dummies setoriais, de acordo com a } \\
\text { Classificação proposta pelo } \\
\text { Economatica®, o que totalizou } 15 \\
\text { setores para a amostra da pesquisa. }\end{array}$ & Em aberto \\
\hline Trimestre do ano & Controle & Dummies trimestrais $\left(1^{\circ}, 2^{\circ}, 3^{\circ}\right.$ e $\left.4^{\circ}\right)$ & Em aberto \\
\hline
\end{tabular}

Fonte: Elaborada pelos autores.

Os dados financeiros utilizados para a estimação dos accruals discricionários e a proximidade de violação dos covenants contábeis foram coletados da base de dados do software Economaticaß. $O$ acompanhamento da proximidade de violação técnica e o gerenciamento de resultados ocorreram para o período de março de 2010 a setembro de 2017.

Os dados foram tabulados em observações trimestrais. Isto se justifica por conta de que aproximadamente $65 \%$ dos covenants contábeis utilizados das debêntures emitidas no Brasil são verificados trimestralmente pelos credores (Konraht, 2017). Assim, a utilização de dados trimestrais é mais eficiente para captar o gerenciamento de resultados para evitar a violação técnica dos covenants, pois as observações estão mais próximas da data real de verificação dos covenants e, assim, captam com maior precisão os incentivos dos gestores em evitar a violação técnica da dívida. Esse procedimento mitiga o viés destacado por Jha (2013), de que as observações anvais são deturbadas por vários incentivos aos gestores gerenciarem os resultados, bem como não captam com precisão o gerenciamento de resultados para evitar a violação técnica, uma vez que a violação não necessariamente ocorre somente no quarto trimestre do ano.

Para a análise dos dados foi considerada a duração efetiva dos títulos de dívida até a ocorrência da primeira violação técnica (inclusive) ou resgate do título. A análise da duração efetiva se justifica por conta de que alguns títulos poderem ter sido resgatados antecipadamente em relação ao prazo definido na escritura ou prospecto de debênture, o que elimina a obrigatoriedade de cumprimento dos covenants a partir da data do resgate. Já a análise até a primeira violação se justifica por conta dos incentivos dos gestores serem maiores 
para evitar a primeira violação da dívida do que as seguintes (Dichev \& Skinner, 2002), bem como pelo fato de que geralmente os termos da dívida, inclusive os covenants, serem renegociados e modificados após a violação dos covenants (Silva, 2008).

Por meio da análise box plot (método de intervalo interquartílico), foi constatada a presença de observações influentes na amostra. O tratamento adotado foi a winsorização das variáveis com o critério de corte de $1 \%$ em cada extremidade de distribuição das variáveis.

Por fim, cabe destacar as diferenças metodológicas deste estudo em relação ao de Silva (2008), realizado anteriormente no Brasil. A principal diferença consiste na mensuração da variável dependente, representativa da resposta dos gestores frente à proximidade de violação técnica dos covenants contábeis, em que Silva (2008) a mensurou pelas mudanças de políticas contábeis realizadas e evidenciadas pelas empresas em notas explicativas, enquanto nesta pesquisa ela foi operacionalizada pelo gerenciamento de resultados através de accruals discricionários. Além dessa diferença principal, também diferem o período de análise, em que Silva (2008) analisou dados de 2000 a 2006 (pré-IFRS), e a amostra, em que Silva (2008) observou as companhias registradas na Comissão de Valores Mobiliários que deveriam cumprir covenants contábeis em emissões de debêntures e financiamentos bancários captados junto a um grande banco público federal (Silva, 2008). A variável de interesse, proximidade de violação, é calculada de forma similar ao procedimento adotado por Silva (2008), com adaptação aos indicadores financeiros desta pesquisa, de modo a refletir a proximidade de violação em termos percentuais.

\section{ANÁLISE E DISCUSSÃO DOS RESULTADOS}

\subsection{Estatísticas Descritivas}

Na Tabela 3 apresentam-se as estatísticas descritivas das observações que integraram ao menos um dos modelos de regressão da etapa de análise inferencial da pesquisa. Esse critério explica a diferença no número de observações (N) entre as variáveis. 
Tabela 3

Estatísticas descritivas das variáveis analisadas na pesquisa

\begin{tabular}{c|c|c|c|c|c|c|c|c|c|c}
\hline Variável & $\mathbf{N}$ & $\mathbf{n}$ & Média & $\mathbf{D P}$ & $\mathbf{C V}$ & Mín & $\mathbf{Q 1}$ & Md & Q3 & Máx \\
\hline $\begin{array}{c}\text { DL/EBITDA - } \\
\text { Proximidade de } \\
\text { violação (\%) }\end{array}$ & 1119 & 92 & $-40,0$ & 28,0 & 70,2 & $-109,5$ & $-61,1$ & $-40,5$ & $-19,5$ & 77,6 \\
\hline $\begin{array}{c}\text { DL/EBITDA - Violado } \\
\text { (primeira violação) }\end{array}$ & 1119 & 92 & $3,01 \%$ & - & - & 0 & 0 & 0 & 0 & 1 \\
\hline $\begin{array}{c}\text { DL/PL - Proximidade } \\
\text { de violação (\%) }\end{array}$ & 148 & 13 & $-39,8$ & 26,0 & 65,3 & $-109,8$ & $-58,6$ & $-43,9$ & $-20,6$ & 20,6 \\
\hline $\begin{array}{c}\text { DL/PL - Violado } \\
\text { (primeira violação) }\end{array}$ & 148 & 13 & $4,73 \%$ & - & - & 0 & 0 & 0 & 0 & 1 \\
\hline $\begin{array}{c}\text { GR Jones Modificado } \\
\text { Tamanho da } \\
\text { empresa (R\$ bilhões) }\end{array}$ & 1223 & 100 & $-0,05$ & 0,04 & 0,76 & $-0,14$ & $-0,07$ & $-0,05$ & $-0,02$ & 0,12 \\
\hline Endividamento (\%) & 1223 & 100 & 7,10 & 9,83 & 1,39 & 0,31 & 1,75 & 3,64 & 6,92 & 68,7 \\
\hline $\begin{array}{c}\text { Crescimento das } \\
\text { vendas (\%) }\end{array}$ & 1223 & 100 & 2,35 & 13,9 & 0,23 & 26,0 & 51,7 & 60,8 & 71,6 & 96,8 \\
\hline Rentabilidade (\%) & 1223 & 100 & 1,30 & 1,53 & 1,17 & $-6,22$ & 0,19 & 1,00 & 2,21 & 6,68 \\
\hline Nota: Grupo viodo con
\end{tabular}

Nota: Grupo violado corresponde ao grupo de empresas que apresentaram desempenho $10 \%$ acima do limite estabelecido para o covenant contábil.

Legenda: N: quantidade de observações; n: quantidade de empresas; DP: desvio padrão; Mín: menor valor; Q1: primeiro quartil; Md: mediana; Q3: terceiro quartil; Máx: maior valor. DL: Dívida líquida; EBITDA: Lucro Antes dos Juros, Tributos Sobre o Lucro, Depreciação e Amortização; PL: Patrimônio líquido; GR: Gerenciamento de resultados.

Fonte: Elaborada pelos autores.

Observa-se que tanto o indicador Dívida Líquida/EBITDA (DL/EBITDA) quanto o indicador Dívida Líquida/Patrimônio Líquido (DL/PL) apresentam valores similares em relação à proximidade de violação técnica, dado que a proximidade média destes indicadores foi de aproximadamente $-40 \%$ (o que corresponde a estarem $40 \%$ abaixo no limite máximo).

Porém, constatou-se que o indicador DL/PL foi o que apresentou maior proporção relativa de casos de primeira violação, sendo que em $4,7 \%$ das observações a situação financeira da empresa se situou aquém do limite estabelecido neste covenant contábil. Essa constatação atualiza os achados de Silva (2008), em que o autor havia documentado que, para o período de 2000 a 2006, o indicador de índice de endividamento apresentava a maior quantidade de violações técnica nas debêntures emitidas no Brasil. O indicador DL/EBITDA apresentou $3 \%$ de casos com primeira violação técnica da dívida. Destaca-se que os eventos de primeira violação técnica da dívida são específicos de cada título de dívida emitido pelas empresas, sendo que uma mesma empresa pode apresentar mais de um título violado ao longo da série temporal analisada.

\subsection{Análises Inferenciais}

Posteriormente à coleta, tabulação e análise exploratória dos dados, foram realizadas as análises inferenciais por meio de análises de regressão com dados em painel. Foram estimados dois modelos para a pesquisa, sendo a diferença entre eles apenas na subamostra, a qual é delimitada pelos indicadores: (a) Dívida Líquida/EBITDA (DL/EBITDA); (b) Dívida Líquida/Patrimônio Líquido (DL/PL). 
Para o diagnóstico do tipo de modelo de dados em painel mais adequado para cada regressão, foram realizados os testes de Breusch-Pagan, de Hausman e de Chow para verificar a adequação dos modelos Pooled, efeitos fixos ou aleatórios. Os resultados desses testes, bem como os parâmetros estimados nos modelos são apresentados na Tabela 4.

\section{Tabela 4}

Resultados das análises de regressão

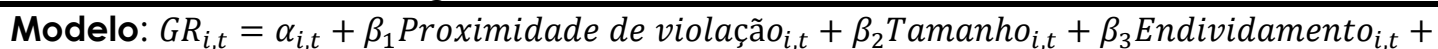
$\beta_{4}$ Crescimento das vendas $_{i, t}+\beta_{5}$ Rentabilidade $_{i, t}+\sum_{k=1}^{4} \delta_{k}$ TRIMESTRE $_{k}+\sum_{d=2010}^{2017} \theta_{d}$ ANO $_{d}+$

\begin{tabular}{|c|c|c|c|c|}
\hline Indicador do covenant & \multicolumn{2}{|c|}{ Dívida Líquida/EBITDA } & \multicolumn{2}{|c|}{ Dívida líquida/PL } \\
\hline Variáveis & Coef. & Sig. & Coef. & Sig \\
\hline Proximidade de violação & $\begin{array}{l}0,019 \\
(2,87)\end{array}$ & 0,004 & $\begin{array}{l}0,051 \\
(2,83)\end{array}$ & 0,005 \\
\hline Tamanho & $\begin{array}{l}-0,002 \\
(-0,85)\end{array}$ & 0,397 & $\begin{array}{l}0,015 \\
(3,58)\end{array}$ & $<0,01$ \\
\hline Endividamento & $\begin{array}{l}-0,027 \\
(-1,98)\end{array}$ & 0,047 & $\begin{array}{l}-0,095 \\
(-2,23)\end{array}$ & 0,027 \\
\hline Crescimento das vendas & $\begin{array}{l}-0,024 \\
(-2,27)\end{array}$ & 0,023 & $\begin{array}{l}-0,007 \\
(-0,53)\end{array}$ & 0,600 \\
\hline Rentabilidade & $\begin{array}{l}0,451 \\
(5,11)\end{array}$ & $<0,01$ & $\begin{array}{l}0,772 \\
(0,29)\end{array}$ & 0,010 \\
\hline Constante & $\begin{array}{l}0,251 \\
(0,70)\end{array}$ & 0,487 & $\begin{array}{l}-0,177 \\
(-2,92)\end{array}$ & 0,004 \\
\hline Efeito fixo para trimestre & \multicolumn{2}{|c|}{ Sim } & \multicolumn{2}{|c|}{ Sim } \\
\hline Efeito fixo para ano & \multicolumn{2}{|c|}{ Sim } & \multicolumn{2}{|c|}{ Sim } \\
\hline Efeito fixo para setor & \multicolumn{2}{|c|}{ Sim } & \multicolumn{2}{|c|}{ Sim } \\
\hline Quantidade de observações & \multicolumn{2}{|c|}{1119} & \multicolumn{2}{|c|}{148} \\
\hline Quantidade de empresas & \multicolumn{2}{|c|}{92} & \multicolumn{2}{|c|}{13} \\
\hline Teste Wald $\left(x^{2}\right)$ & \multicolumn{2}{|c|}{$176,82^{* * *}$} & \multicolumn{2}{|c|}{-} \\
\hline Teste $F(F)$ & \multicolumn{2}{|c|}{-} & \multicolumn{2}{|c|}{$10,33^{* * *}$} \\
\hline Teste Shapiro-Francia (z) & \multicolumn{2}{|c|}{$8,43^{* * *}$} & \multicolumn{2}{|c|}{$2,61^{* * *}$} \\
\hline $\mathrm{R}^{2}$ overall & \multicolumn{2}{|c|}{0,243} & \multicolumn{2}{|c|}{-} \\
\hline $\mathrm{R}^{2}$ ajustado & \multicolumn{2}{|c|}{-} & \multicolumn{2}{|c|}{0,485} \\
\hline Tipo do modelo & \multicolumn{2}{|c|}{ Efeitos aleatórios } & \multicolumn{2}{|c|}{ Pooled } \\
\hline Teste Breusch-Pagan $\left(x^{2}\right)$ & \multicolumn{2}{|c|}{$537,24^{* * *}$} & \multicolumn{2}{|c|}{0,00} \\
\hline Teste de Chow $(F)$ & \multicolumn{2}{|c|}{$9,38^{* * *}$} & \multicolumn{2}{|c|}{$9,59 * * *$} \\
\hline Teste de Hausman $\left(X^{2}\right)$ & \multicolumn{2}{|c|}{14,44} & \multicolumn{2}{|c|}{$20,50 * * *$} \\
\hline
\end{tabular}

Nota: Os valores apresentados entre parênteses correspondem às estatísticas $t$ dos coeficientes. Os parâmetros dos modelos foram estimados com erros-padrão robustos, conforme método de correção de Huber-White, dado que o teste de Wald indicou a presença de heterocedasticidade nos modelos. Os modelos também apresentaram indícios de ausência de normalidade dos resíduos, porém este pressuposto foi relaxado uma vez que, de acordo com o teorema do limite central, em amostras grandes este pressuposto pode ser relaxado (Wooldridge, 2014). A significância estatística foi calculada considerando a probabilidade bicaudal de distribuição. Optou-se por analisar o indicador DL/PL com regressão pooled, apesar dos testes sugerirem o uso de efeitos fixos, dado que estimação pooled permite fixar os efeitos dos setores, enquanto a de efeitos fixos os suprime; porém, rodando esta regressão com efeitos fixos, os resultados não foram alterados.

Legenda: PL: Patrimônio Líquido.

Fonte: Elaborado pelos autores. 
A partir dos resultados apresentados na Tabela 4, é constatado, primeiramente, a validade geral dos modelos estimados, dado que os valores dos testes Wald $X^{2}$ e $F$ se apresentaram estatisticamente significantes ao nível de confiança de $99 \%$ ( $p$-valor $<0,01)$. Ademais, é constatado que a proximidade de violação técnica da dívida apresenta relação positiva com o volume de accruals discricionários. Esses resultados são estatisticamente significantes ao nível de confiança de $99 \%$ ( $p$-valor $<0,01$ ) para ambos os indicadores testados na pesquisa.

Esses resultados apresentam indícios de que os gestores respondem contabilmente ao risco de violação dos covenants contábeis por meio da utilização da sua discricionariedade sobre os critérios contábeis para aumentar o resultado por meio dos accruals discricionários e, assim, tentar evitar a violação técnica da dívida e as consequências econômicas decorrentes dela. Tais resultados estão alinhados às evidências obtidas no mercado de crédito bancário dos Estados Unidos (DeFond \& Jiambalvo, 1994; Jaggi \& Lee, 2002; Jha, 2013; Franz et al., 2014), o que indica que as consequências econômicas da violação técnica das debêntures também geram incentivos para que os gestores adotem estratégias contábeis para evita-las.

Ademais, esse comportamento dos gestores é consistente tanto para o indicador capital covenant (DL/PL) quanto para o indicador performance covenant (DL/EBITDA). Assim, depreende-se que, embora essas duas classes de covenants tenham finalidades distintas e os performance covenants tenham como característica a maior facilidade de renegociação da dívida em caso de violação técnica da dívida (Christensen \& Nikolaev, 2012), os gestores despendem esforços para evitar os custos decorrentes da violação técnica de ambos. Isso pode ser explicado por conta de que mesmo que a probabilidade de renegociação da violação dos performance covenants seja maior do que a dos capital, ambas geram custos à empresa e seus gestores.

Especificamente, pela forma como as penalizações da violação técnica são especificadas nas escrituras e prospectos de debêntures emitidas no Brasil, tem-se que, para a empresa conseguir receber o perdão para a violação dos covenants contábeis, é necessária, na maior parte dos casos, a aprovação de, no mínimo, $75 \%$ dos debenturistas reunidos em Assembleia Geral, convocada para deliberar especificamente sobre a eventual concessão de perdão à violação (Konraht, 2017). Ademais, mesmo que a empresa receba o perdão para a violação técnica, geralmente ocorre a modificação ou inclusão de novas cláusulas restritivas nos contratos (Silva, 2008), além da possibilidade do perdão ser negado pelos debenturistas, o que obriga a empresa a antecipar o resgate da dívida. Consequentemente, o risco de violação técnica de ambas as classes de covenants gera incentivos para gerenciamento de resultados na tentativa de evitar a violação técnica da dívida.

Por outro lado, os resultados dessa pesquisa não convergem com os encontrados por Silva (2008), o qual analisou a realização de mudanças nas práticas contábeis evidenciadas em notas explicativas para evitar a violação dos covenants contábeis, e não encontrou relação entre as mudanças e proximidade de violação. Considerando que a pesquisa atual e a pesquisa de Silva (2008) possuem comparação limitada, por conta de utilizarem métodos e pressupostos distintos, essa divergência de resultados pode ser explicada por ao menos dois fatores, os quais são: (a) estratégia contábil adotada para evitar a 
violação; e, (b) maior oportunidade de gerenciamento de resultados após a modificação das normas contábeis brasileiras em 2010. Primeiramente, a constatação da pesquisa atual de que os gestores utilizam os accruals discricionários para evitar a violação dos covenants sinaliza uma possível preferência dos gestores pela estratégia de manipular accruals discricionários por meio de políticas contábeis implícitas, em detrimento de alterar voluntariamente políticas contábeis evidenciadas em notas explicativas para evitar a violação técnica. Esse fenômeno ainda carece de evidências empíricas complementares para que possa ser confirmado, uma vez que tanto as políticas contábeis evidenciadas em notas explicativas quanto as não evidenciadas impactam nos accruals discricionários; porém há fatores que contribuem para que as empresas prefiram praticar mudanças de políticas contábeis implícitas para gerenciar resultados ao invés de realizarem mudanças de políticas contábeis explicitadas em notas explicativas. Dentre esses fatores, se destacam os seguintes: (a) a estratégia de gerenciar os accruals discricionários por meio de políticas contábeis implícitas é menos custosa (DeFond \& Jiambalvo, 1994) e menos visível (Healy \& Palepu, 1990) do que a modificação voluntária de políticas contábeis evidenciadas em notas explicativas; e, (b) muitas empresas já adotam políticas contábeis explícitas agressivas (Silva, 2008), assim elas não possuem flexibilidade suficiente para alterar essas políticas, o que as leva a adotar a estratégia de gerenciar os accruals discricionários por meio de procedimentos relacionados à mensuração e reconhecimento dos elementos contábeis não evidenciados em notas explicativas.

O outro fator que pode ter sido responsável pela diferença dos achados da presente pesquisa com os da pesquisa de Silva (2008) são as mudanças das normas de contabilidade ocorridas em 2010. Assim, a maior discricionariedade e subjetividade na aplicação dos critérios de mensuração de ativos e passivos, após a harmonização da contabilidade brasileira ao padrão International Financial Reporting Standards (IFRS), pode ter contribuído para que os gestores passassem a ter oportunidade suficiente para gerenciar os resultados para evitar a violação técnica da dívida, devido à interpretabilidade requerida pelas IFRSs.

Dentre as limitações desta pesquisa, tem-se que estas duas potenciais explicações são hipotéticas e não foram testadas na presente pesquisa. Assim, ressalta-se a importância da realização de estudos adicionais que utilizem como ponto de partida as evidências desta pesquisa e a de Silva (2008), com a finalidade de testar estas potenciais explicações e contribuir para a melhor compreensão da resposta contábil adotada pelas empresas frente à iminência de violação dos covenants. Além disso, como esta pesquisa limita-se a analisar o gerenciamento por accruals discricionários, é profícuo que estudos futuros se proponham explorar a hipótese de as empresas adotarem a estratégia de realizar decisões operacionais para evitar a violação técnica da dívida, uma vez que os gestores também podem adotá-la para tentar evitar a violação técnica da dívida.

\subsection{Testes Adicionais}

Foram realizados testes adicionais aos apresentados na Tabela 4 para avaliar a consistência dos resultados obtidos. Para o indicador DL/EBITDA, foram estimadas regressões usando pooled com efeitos fixos para trimestre, ano e setor; 
enquanto para o indicador DL/PL foram estimadas regressões usando efeitos fixos. Os resultados encontrados a partir destas novas regressões não apresentaram alteração na variável de interesse, ao nível de confiança de 95\% ( $p$-valor<0,05).

Outro teste adicional foi a estimação dos accruals discricionários usando como amostra somente as empresas que possuíam os covenants DL/EBITDA e DL/PL nas debêntures levantadas na pesquisa. Os resultados da variável de interesse também se mantiveram estáveis, ao nível de confiança de $93 \%$ ( $p$ valor<0,10), indicando consistência dos resultados.

Por fim, foram realizados testes usando a variável proximidade de violação defasada em até quatro trimestres. Os resultados não indicaram relação consistente entre GR e proximidade de violação defasada, o que sugere que a prática de gerenciamento para evitar a violação ocorre no trimestre em que o indicador está próximo de ser violado.

\section{CONCLUSÕES}

Este estudo testou a resposta contábil dos gestores frente à proximidade de ocorrência do evento de violação técnica da dívida nas debêntures emitidas no Brasil. Especificamente, foi testada a hipótese de que a proximidade de violação dos covenants contábeis incentiva os gestores a utilizarem accruals discricionários para aumentar o resultado contábil do período. Essa hipótese está embasada nos pressupostos teóricos e evidências empíricas documentadas na literatura de que a violação técnica da dívida gera consequências econômicas negativas à empresa e aos gestores. Consequentemente, a proximidade de violação técnica gera incentivo para que os gestores utilizem o seu poder discricionário sobre os critérios contábeis para aumentar o resultado e, assim, evitar a violação técnica da dívida.

Os resultados obtidos para os covenants inseridos nas debêntures emitidas no Brasil confirmam a hipótese desenvolvida na pesquisa. Especificamente, foi constatado que à medida que a violação dos covenants contábeis se aproxima, maior tende a ser o gerenciamento de resultados praticado pelos gestores para aumentar o resultado contábil.

A principal contribuição teórica desta pesquisa está na constatação de que os gestores adotam a estratégia contábil de manipulação dos accruals discricionários para evitar a violação técnica da dívida. Nesse sentido, esta pesquisa complementa aos achados de Silva (2008), ao indicar que os gestores adotam artifícios contábeis para evitar a violação técnica da dívida. Tomados em conjunto, os resultados dessas duas pesquisas sinalizam que, embora os gestores não adotem alterações de políticas contábeis explícitas para evitar a violação técnica da dívida (Silva, 2008), eles não são neutros ao incentivo de evitar as consequências econômicas negativas decorrentes da violação técnica da dívida e podem estar alterando políticas contábeis não evidenciadas em notas explicativas para atingir esta finalidade.

Para a literatura internacional, esses achados se posicionam como uma adição às evidências empíricas desenvolvidas no mercado de crédito bancário dos Estados Unidos (DeFond \& Jiambalvo, 1994; Jaggi \& Lee, 2002; Jha, 2013; Franz et al., 2014), uma vez que demonstram que o risco de violação técnica das debêntures também gera incentivos suficientes para que os gestores adotem

116 Revista Contabilidade Vista \& Revista, ISSN 0103-734X, Universidade Federal de Minas Gerais, Belo Horizonte, v. 32, n. 2, p. 97-121, maio/ago. 2021 
estratégias contábeis para inflar o resultado do período e evitar as consequências econômicas negativas decorrentes da violação técnica.

A pesquisa também avança ao sinalizar indícios de que a prática de gerenciar resultados é consistente para evitar a violação técnica tanto dos capital covenants quanto dos performance covenants. Esse fenômeno indica que, embora a violação dos capital covenants tenda a ser mais complicada de renegociar com os credores do que a dos performance covenants, ambos geram incentivos para os gestores adotarem artifícios contábeis na tentativa de evitar a violação técnica. No entanto, dada a limitação na quantidade de observações da amostra de capital covenants (DL/PL), os resultados obtidos para esse indicador são limitados e devem ser interpretados apenas como indícios, com baixo poder de generalização.

Os resultados constatados nesta pesquisa abrem caminhos para novos testes no ambiente brasileiro, os quais podem ser exploradas em estudos futuros. Uma possibilidade é a verificação da eficácia do gerenciamento de resultados para evitar a violação técnica dos covenants contábeis, atrasando-a, evitandoa ou fornecendo tempo suficiente para a firma recuperar a saúde econômicofinanceira. Outra vertente poderia ser a verificação de estratégias contábeis adotadas pelos gestores na tentativa de evitar a violação técnica de covenants contábeis, tal como decisões operacionais. A exploração dessas lacunas em pesquisas futuras contribuirá para aumentar o entendimento científico sobre os incentivos, respostas e consequências da relação entre gerenciamento de resultados e violação de covenants contábeis no ambiente brasileiro.

\section{REFERÊNCIAS}

Ardison, K. M. M., Martinez, A. L., \& Galdi, F. C. (2012). The effect of leverage on earnings management in Brazil. Advances in Scientific and Applied Accounting, 5(3), 305-324. http://dx.doi.org/10.14392/ASAA/2012050301

Ball, R., Li, X., \& Shivakumar, L. (2015). Contractibility and Transparency of Financial Statement Information Prepared Under IFRS: Evidence from Debt Contracts Around IFRS Adoption. Journal of Accounting Research, 53(5). https://doi.org/10.1111/1475-679X.12095

Barros, C. M. E., Menezes, J. T., Colauto, R. D., \& Teodoro, J. D. (2014). Gerenciamento de Resultados e Alavancagem financeira em Empresas Brasileiras de Capital Aberto. Contabilidade, Gestão e Governança, 17(1), 3555.

Beiruth, A. X., Fávero, L. P. L., Murcia, F. D.-R., de Almeida, J. E. F., \& Brugni, T. (2017). Structural changes in covenants through the adoption of IFRS in Brazil. Accounting Forum, 41(3), 147-160. http://dx.doi.org/10.1016/i.accfor.2017.06.004

Beneish, M. D., \& Press, E. G. (1993). Costs of Technical Violation of AccountingBased Debt Covenants. The Accounting Review, 68(2), 233-257. http://dx.doi.org/10.2307/248399 
Bhaskar, L. S., Krishnan, G. V., \& Yu, W. (2017). Debt Covenant Violations, Firm Financial Distress, and Auditor Actions. Contemporary Accounting Research, 34(1), pp. 186-215. http://dx.doi.org/10.1111/1911-3846.12241

Bulan, L., \& Hull, T. (2013). The impact of technical defaults on dividend policy. Journal of Banking and Finance, 37(3), pp. 814-823. https://doi.org/10.1016/i.jbankfin.2012.10.014

Chava, S., Fang, S., Kumar, P., \& Prabhat, S. (2019). Debt Covenants and Corporate Governance. Annual Review of Financial Economics, 11(1), 197-219. https://doi.org/10.1146/annurev-financial-110716-032511

Chen, K. C. W., \& Wei, J. K. C. (1993). Creditors' Decisions to Waive Violations of Accounting-Based Debt Covenants. The Accounting Review, 68(2), pp. 218232. https://doi.org/10.2307/248398

Christensen, H. B., \& Nikolaev, V. V. (2012). Capital Versus Performance Covenants in Debt Contracts. Journal of Accounting Research, 50(1), pp. 75-116. https://doi.org/10.1111/j.1475-679X.2011.00432.x

Coelho, A. C. D., \& Lopes, A. B. (2007). Avaliação da prática de gerenciamento de resultados na apuração de lucro por companhias abertas brasileiras conforme seu grau de alavancagem financeira. Revista de Administração Contemporânea, 11(2), 121-144. http://dx.doi.org/10.1590/S1415$\underline{65552007000600007}$

Dechow, P. M., Sloan, R. G., \& Sweeney, A. P. (1995). Detecting Earnings Management. The Accounting Review, 70(2), pp. 193-225. http://dx.doi.org/10.2307/248303

DeFond, M. L., \& Jiambalvo, J. (1994). Debt covenant violation and manipulation of accruals. Journal of Accounting and Economics, 17(1-2), pp. 145-176. http://dx.doi.org/10.1016/0165-4101(94)90008-6

Demerjian, P. R. (2011). Accounting standards and debt covenants: Has the "balance sheet approach" led to a decline in the use of balance sheet covenants? Journal of Accounting and Economics, 52(2-3), pp. 178-202. https://doi.org/10.1016/j.jacceco.2011.08.004

Demerjian, P. R. (2017). Uncertainty and debt covenants. Review of Accounting Studies, 22 (3), pp. 1156-1 197. https://doi.org/10.1007/s1 1142-017-9409-z

Dichev, I. D., \& Skinner, D. J. (2002). Large-Sample Evidence on the Debt Covenant Hypothesis. Journal of Accounting Research, 40(4), pp. 1091-1123. https://doi.org/10.1111/1475-679X.00083

Franz, D. R., HassabElnaby, H. R., \& Lobo, G. J. (2014). Impact of proximity to debt covenant violation on earnings management. Review of Accounting Studies, 19(1), pp. 473-505. https://doi.org/10.1007/s $11142-013-9252-9$ 
Freudenberg, F., Imbierowicz, B., Saunders, A., \& Steffen, S. (2017). Covenant violations and dynamic loan contracting. Journal of Corporate Finance, 45, pp. 540-565. http://dx.doi.org/10.1016/i.j.jcorpfin.2017.05.009

Gao, Y., Khan, M., \& Tan, L. (2017). Further Evidence on Consequences of Debt Covenant Violations. Contemporary Accounting Research, 34(3), pp. 14891521. https://doi.org/10.1111/1911-3846.12303

Gu, Z., Lee, C. W. J., \& Rosett, J. G. (2005). What determines the variability of accounting accruals? Review of Quantitative Finance and Accounting, 24(3), 313-334. http://dx.doi.org/10.1007/s $11156-005-6869-1$

Healy, P. M., \& Palepu, K. G. (1990). Effectiveness of accounting-based dividend covenants. Journal of Accounting and Economics, 12(1-3), pp. 97-123. http://dx.doi.org/10.1016/0165-4101(90)90043-4

Hong, H. A., Hung, M., \& Zhang, J. (2016). The Use of Debt Covenants Worldwide: Institutional Determinants and Implications on Financial Reporting. Contemporary Accounting Research, 33(2), 644-681. https://doi.org/10.1111/1911-3846.12169

Jaggi, B., \& Lee, P. (2002). Earnings Management Response to Debt Covenant Violations and Debt Restructuring. Journal of Accounting, Auditing \& Finance, 17(4), pp. 295-324. http://dx.doi.org/10.1177/0148558X0201700402

Jha, A. (2013). Earnings Management Around Debt-Covenant Violations - An Empirical Investigation Using a Large Sample of Quarterly Data. Journal of Accounting, Auditing \& Finance, 28(4), pp. 369-396. https://doi.org/10.1177/0148558X13505597

Jones, J. J. (1991). Earnings Management During Import Relief Investigations. Journal of Accounting Research, 29(2), pp. 193-228. http://dx.doi.org/10.2307/2491047

Konraht, J. M. (2017). Determinantes da utilização dos covenants contábeis nas debêntures emitidas pelas empresas listadas na BM\&FBOVESPA (Dissertação de Mestrado). Universidade Federal de Santa Catarina, Florianópolis, SC, Brasil.

Mather, P., \& Peirson, G. (2006). Financial covenants in the markets for public and private debt. Accounting and Finance, 46(2), pp. 285-307. http://dx.doi.org/10.1111/j.1467-629X.2006.00168.x

Ngo, A., Duong, H., \& Chen, A. (2016). The Effects of Covenant Violations on the Underpricing of Seasoned Equity Offerings and the Implied Cost of Equity Capital. Quarterly Journal of Finance, 6(1), pp. 1-33. https://doi.org/10.1142/S2010139216400036 
Nini, G., Smith, D. C., \& Sufi, A. (2012). Creditor control rights, corporate governance, and firm value. Review of Financial Studies, 25(6), pp. 1713-1761. https://doi.org/10.1093/rfs/hhs007

Nardi, P. C. C., Nakao, S. H., Carolina, P., \& Nardi, C. (2009). Gerenciamento de resultados e a relação com o custo da dívida das empresas brasileiras abertas. Revista Contabilidade \& Finanças, 20(51), 77-100. http://dx.doi.org/10.1590/S1519-70772009000300006

Richardson, V. J. (2000). Information Asymmetry and Earnings Management: Some Evidence. Review of Quantitative Finance and Accounting, 15(4), 325-347. http://dx.doi.org/10.1023/A:1012098407706

Silva, A. H. C. e. (2008). Escolha de práticas contábeis no Brasil: uma análise sob a ótica da hipótese dos covenants contratuais (Tese de Doutorado). Universidade de São Paulo, São Paulo, SP, Brasil.

Smith, C. W., \& Warner, J. B. (1979). On Financial Contracting: An Analysis of Bond Convenants. Journal of Financial Economics, 7(2), pp. 117-161. http://dx.doi.org/10.1016/0304-405X(79)90011-4

Sincerre, B. P., Sampaio, J. O., Famá, R., \& Santos, J. O. dos. (2016). Emissão de Dívida e Gerenciamento de Resultados. Revista Contabilidade \& Finanças, 27(72), 291-305. http://dx.doi.org/10.1590/1808-057x201601660

Sweeney, A. P. (1994). Debt-covenant violations and managers' accounting responses. Journal of Accounting and Economics, 17(3), pp. 281-308. https://doi.org/10.1016/0165-4101(94)90030-2

Taylor, P. (2013). What do we know about the role of financial reporting in debt contracting and debt covenants? Accounting and Business Research, 43(4), pp. 386-417. https://doi.org/10.1080/00014788.2013.798551

Watts, R. L., \& Zimmerman, J. L. (1990). Accounting Year Theory: Ten Perspective. The Accounting Review. pp. 131-156. http://dx.doi.org/10.2307/247880

Wooldridge, J. M. (2014). Introdução à econometria: uma abordagem moderna. (4. ed.) São Paulo: Cengage Learning. 


\section{CONTRIBUIÇÕES DOS AUTORES}

\begin{tabular}{|l|c|c|}
\hline \multicolumn{1}{|c|}{ Contribuição } & $\begin{array}{c}\text { Jonatan Marlon } \\
\text { Konraht }\end{array}$ & $\begin{array}{c}\text { Romualdo } \\
\text { Douglas Colauto }\end{array}$ \\
\hline $\begin{array}{l}\text { 1. Idealização e concepção do assunto e tema da } \\
\text { pesquisa }\end{array}$ & $\checkmark$ & $\checkmark$ \\
\hline 2. Definição do problema de pesquisa & $\checkmark$ & $\checkmark$ \\
\hline 3. Desenvolvimento da Plataforma Teórica & $\checkmark$ & $\checkmark$ \\
\hline $\begin{array}{l}\text { 4. Delineamento da abordagem metodológica da } \\
\text { pesquisa }\end{array}$ & $\checkmark$ & $\checkmark$ \\
\hline 5. Coleta de dados & $\checkmark$ & \\
\hline 6. Análises e interpretações dos dados coletados & $\checkmark$ & $\checkmark$ \\
\hline 7. Conclusões da pesquisa & $\checkmark$ & $\checkmark$ \\
\hline 8. Revisão crítica do manuscrito & $\checkmark$ & $\checkmark$ \\
\hline $\begin{array}{l}\text { 9. Redação final do manuscrito, conforme as normas } \\
\text { estabelecidas pela Revista. }\end{array}$ & & $\checkmark$ \\
\hline 10. Orientação & & \\
\hline
\end{tabular}

